\title{
A Study to Evaluate the Effectiveness of Acupressure on Quality of Sleep among the Elderly in Selected Old Age Home at Mangalore, Karnataka
}

\author{
T. Denitha', Johncy Rodrigues ${ }^{2}$ \\ ${ }^{1}$ Department of Medical Surgical Nursing, Father Muller College of Nursing, Mangalore, Karnataka, India, ${ }^{2}$ Department of Medical Surgical Nursing department, Dr. M. \\ V. Shetty College of Nursing, Mangalore, Karnataka, India
}

\section{Abstract}

Background: A large percentage of elderly people suffer from chronic insomnia, affecting many aspects of life in the elderly. Surveys show that more than $50 \%$ of old age people experience sleep disturbance. This condition is underrecognized, underdiagnosed, and undertreated in the general population. These facts give strong drive to think about an alternate way to treat this kind of conditions. It is assumed that the acupressure is an alternative therapy which will aid in promoting good quality of sleep.

Materials and Methods: A quasi-experimental study design was used. The sample comprised 40 elderly with poor quality of sleep which was assessed using Pittsburgh Sleep Quality Index. Non-probability purposive sampling technique was used. The investigator taught acupressure to the experimental group and it was practiced once daily for 15 days. Post-test was conducted, data were analyzed using descriptive and inferential statistics.

Results: The mean post-test score $(4.2 \pm 0.4)$ was less than that of mean pre-test score $(8.15 \pm 1.27)$ in the experimental group, whereas in the control group, the mean post-test score $(8.3+1.67)$ was almost similar to the mean pre-test scores $(8.4+1.32)$. The findings revealed that the calculated $t$-value $(15.41)$ was greater than the table value $\left(t_{19}=2.09\right)$ at 0.05 level of significance. Unpaired t-test was used to analyze the difference in post-test scores of the experimental and control groups. The findings revealed that the calculated " $t$ "-value (10.58) was greater than the table value $\left(t_{38}=2.02\right)$ at 0.05 level of significance.

Conclusion: The researcher concludes that there was a significant improvement in quality of sleep after the acupressure therapy.

Keywords: Elderly, quality of sleep, acupressure, Pittsburgh sleep quality index

\section{INTRODUCTION}

Globally, the population are aging. The number of older adults is globally expected to increase from 420 million in 2000 to 974 million in 2030. ${ }^{[1]}$ Insomnia, daytime sleepiness, and napping are all highly prevalent among the older adults. ${ }^{[2]}$ Sleep problem in the elderly is often mistakenly considered a normal part of aging. Insomnia, the most common sleep

\section{Access this article online}

Website: http://innovationalpublishers.com/Journal/ijnmi

ISSN No: $2656-4656$

DOI: $10.31690 /$ ijnmi.2020.v05i03.002 disorder, is a subjective report of insufficient or nonrestrictive sleep despite adequate opportunity to sleep. Despite the fact that more than $50 \%$ of elderly people have insomnia, it is typically undertreated and no pharmacological interventions are undertaken by health-care practitioners. ${ }^{[3]}$

India has acquired the label of "an aging nation" with $7.7 \%$ of its population being more than 60 years old. Geriatric clients spend more time in bed than younger ones, but nighttime sleep is typically shallow and disrupted. Although insomnia is most often treated with medication, a growing number of studies demonstrate the efficiency of various relaxation techniques. Globally, the proportion of people aged 60 years and over is growing faster than any other age group. By the year 2025,

This is an open-access journal, and articles are distributed under the terms of the Creative Commons Attribution Noncommercial Share Alike 4.0 License, which allows others to remix, tweak, and build upon the work non-commercially, as long as appropriate credit is given and the new creations are licensed under the identical terms 
people in this age group will reach a total of 1.2 billion and this will rise to 2 billion in the year 2050 with $80 \%$ of them living in developing countries. ${ }^{[4]}$

Researchers from Warwick medical school looked at the sleep quality of 24,434 women and 19,501 men aged 50 years and above - in eight rural global locations such as Ghana, Tanzania, South Africa, India, Bangladesh, Vietnam, Indonesia, and Kenya. Researchers found $16.6 \%$ of the population suffered from insomnia and other severe sleep disturbances in the countries surveyed and about $20 \%$ found in the general adults population in the west. The finding suggests that sleeplessness epidemic affects an estimated 150 million in developing world. These findings as well various other related studies ${ }^{[5-7]}$ emphasize the global dimension of sleep problems as an emerging public health issue. ${ }^{[8,9]}$

The WHO slogan "it is not sufficient to add years to life, but it is more important to add life to years." The prevalence of sleep disorders in older age group is about $50 \%$. Hence, old age people are the victims, who suffer with sleeping disorder ${ }^{8}$. Acupressure is an alternative therapy which is effective in the relief of stress-related ailments. The investigator's personal experience with the elderly made her realize the importance of promoting sleep by nursing interventions and other measures and designed a study with acupressure therapy on sleep quality of the elderly in the old age homes of Mangalore.

\section{Objectives of the study}

The objectives of the study were to:

1. Determine the quality of sleep among the elderly using Pittsburgh Sleep Quality Index (PSQI) in the experimental and control groups.

2. Find the effectiveness of acupressure on quality of sleep among the elderly in the experimental group.

3. Find the association between post-test PSQI score in the experimental group and selected baseline variables

\section{Hypothesis}

The hypothesis will be tested at 0.05 level of significance: $\mathrm{H}_{1} 1$ : There will a significant difference between pre- and post-test quality of sleep scores among the elderly in the experimental group.

$\mathrm{H}_{1}$ 2: There will be a significant difference in the post-test quality of sleep scores between

The experimental and control groups.

$\mathrm{H}_{1} 3$ : There will be significant association between post-test quality of sleep score among the experimental group with selected demographic variables.

\section{Materials and Methods}

\section{Study design and setting}

An evaluative approach and quasi-experimental (nonrandomized control group design) was adopted for the study. The study is conducted in a selected old age home named St. Joseph's Prashanth Nivas, Jeppu at Mangalore.

\section{Sampling size and sampling method}

Non-probability purposive sampling technique was used to select 40 elderly with poor quality of sleep and they were allocated to the experimental and control groups (20 elderly in each) who met the inclusion criteria. The elderly who scores a global sum of $>5$ (PSQI) and those who were willing to participate were included in the study. The elderly who are suffering from chronic illness at the time of data collection and those who are taking medications for sleep were excluded from the study.

\section{Data collection instruments}

\section{Part A}

The baseline data of the subjects were collected using demographic questionnaire comprises 11 items which include age, gender, education, religion, marital status, occupation, reason for joining old age home, habit of doing exercise, having disturbed sleep at night, and taking sleeping pills. The demographic pro forma was given to eight experts from various departments to assess the content validity and correction was incorporated before finalizing the tool.

\section{Part B}

PSQI rating scale used to find out the quality of sleep among the elderly during both pre-test and post-test. It consisted of 19 self-related questions which are combined to form seven components scores of which has a range of $0-3$ points. Then, the seven components are added to yield one global score with the range of $0-21$ points. A total score of " 5 " or greater is indicative of poor sleep quality, $<5$ indicates good quality of sleep. The PSQI has internal consistency and a reliability coefficient (Cronbach's alpha) of 0.83 for its seven components.

\section{Data collection procedure}

Using non-probability purposive sampling and based on inclusion and exclusion criteria, 40 samples were selected, 20 were assigned to the experimental group and 20 to the control group by lottery method. Baseline information were gathered using demographic questionnaire and PSQI, rating scale used to find out the quality of sleep. On the $1^{\text {st }}$ day, the investigator taught acupressure to the experimental group by making the samples to sit on the chair and the technique involves applying firm, controlled and timed pressure on Shenmen point and Shenmai point for 10-15 s followed by $2 \mathrm{~s}$ of relaxation then again applying pressure on same points, this cycle is continued for about $2 \mathrm{~min}$ in each point and informed the samples to practice once daily for 15 days. The entire acupressure therapy took 8-10 min, under supervision of investigator. Post-test was conducted on the $16^{\text {th }}$ day for the experimental as well as the control groups with the same PSQI. The data were collected and recorded systematically and analyzed with descriptive and inferential statistics.

\section{REsults}

\section{Part I: Description of baseline characteristics of the sample}

The data obtained through the demographic questionnaire were analyzed by descriptive statistics. The subject characteristics 
were summarized in using frequency and percentage. Out of 50 subject's, majority (52.5\%) of the participants were in the age group of 75-79 years. Majority (57.5\%) of the samples were female. Among participants, most $(50 \%)$ had secondary education. About $50 \%$ of participants belonged to Christian religion, $50 \%$ of participants belonged to Hindu religion. About $45 \%$ of participants were widowers and $37.5 \%$ were separated. The highest percentages $(52.5 \%)$ were private employees before coming to old age home. The highest percentage $(52.5 \%)$ were neglected by family members. Almost all $(100 \%)$ of the participants have the habit of doing exercise. Majority (72.5\%) of participants were doing exercise weekly. All participants were having disturbed sleep at night and none were taking pills to induce sleep.

\section{Part II: Assessment of pre-test quality of sleep among the elderly in the experimental and control groups}

Data in Table 1 show that after the survey, the highest percentage (100\%) of the elderly had poor quality of sleep.

\section{Part III: Effectiveness of acupressure therapy}

Section A: Comparison of pre-test and post-test scores

of the experimental group

Data in Table 2 show that in the experimental group, all $(100 \%)$ of the elderly had poor quality of sleep in the pre-test, whereas in the post-test, only $20 \%$ of them had poor quality of sleep and $80 \%$ of the elderly had good quality of sleep in the post-test.

The data show that in the experimental group, the mean post-test score $(4.2 \pm 0.4)$ was less than that of the mean pre-test score $(8.15 \pm 1.27)$. To compare the pre-test and post-test quality of sleep scores, paired " $t$ "-test was used. To test the statistical significance, the following null hypothesis was stated [Table 3].

$\mathrm{H}_{0} 1$ : There is no significant difference between pre- and post-test quality of sleep scores among the elderly in the experimental group.

Data in Table 4 show that the mean post-test quality of sleep score $(4.2 \pm 0.4)$ was lower than the mean pre-test score $(8.15 \pm$ 1.27). The calculated $t$-value (15.41) was greater than the table value $\left(t_{19=} 2.09\right)$ at 0.05 level of significance. Hence, the null hypothesis was rejected and research hypothesis is accepted.

Section B: Comparison of pre-test and post-test score of the control group

To compare the pre-test and post-test scores of the control group, frequency and percentage distribution of sample according to the quality of sleep in the control group are calculated.

Data in Table 5 show that all (100\%) of the elderly had poor quality of sleep in pre-test and also same percentage of the elderly had poor quality of sleep in post-test.

The data in Table 6 show that in the control group, the mean post-test score $(8.3 \pm 1.67)$ was almost similar to the mean pre-test $(8.4 \pm 1.32)$.
Section C: Comparison of post-test scores of the experimental and control groups

To compare the post-test scores of the experimental and control groups, frequency and percentage distribution of sample according to the quality of sleep in both the experimental and control groups are calculated.

Data in Table 7 and show that in the experimental group, $80 \%$ of the elderly had good quality of sleep and $20 \%$ of the elderly had poor quality of sleep in post-test, whereas in the control group, $100 \%$ of them had poor quality of sleep.

To test the statistical significance between post-test scores of the experimental and control groups, unpaired $t$-test was computed and the following null hypothesis was stated.

$\mathrm{H}_{0} 2$ : There is no significant difference in the post-test quality of sleep scores between the experimental and control groups.

Data in Table 8 show that the mean post-test quality of sleep score (4.2) in the experimental group after practicing acupressure therapy was lower than the mean post-test score (8.3) in the control group. The calculated $t$-value (10.58) is greater than the table value $\left(t_{38}=2.02\right)$ at 0.05 level of significance. Hence, the null hypothesis was rejected and

Table 1: Frequency and percentage distribution of quality of sleep among the elderly, $n=40$

\begin{tabular}{llccccc}
\hline $\begin{array}{l}\text { Quality } \\
\text { of sleep }\end{array}$ & $\begin{array}{l}\text { Range of } \\
\text { score }\end{array}$ & & \multicolumn{2}{c}{ Experimental group } & & \multicolumn{2}{c}{ Control group } \\
\cline { 3 - 4 } \cline { 6 - 7 } Good & $0-4$ & $\mathbf{F}$ & $\%$ & & $\mathbf{F}$ & $\%$ \\
Poor & $5-21$ & 20 & 100 & & 20 & 100 \\
\hline
\end{tabular}

Table 2: Frequency and percentage distribution of sample according to the quality of sleep level in the experimental group, $n=20$

\begin{tabular}{|c|c|c|c|c|c|}
\hline \multirow{2}{*}{$\begin{array}{l}\text { Quality } \\
\text { of } \\
\text { sleep }\end{array}$} & \multirow{2}{*}{$\begin{array}{c}\text { Range } \\
\text { of } \\
\text { scores }\end{array}$} & \multicolumn{2}{|c|}{ Pre-test } & \multicolumn{2}{|c|}{ Post-test } \\
\hline & & Frequency & Percentage & Frequency & Percentage \\
\hline Good & $0-4$ & - & - & 16 & 80 \\
\hline Poor & $5-21$ & 20 & 100 & 4 & 20 \\
\hline
\end{tabular}

Table 3: Range, mean, median, and SD of pre-test and post-test scores of quality of sleep in the experimental group, $\mathrm{n}=\mathbf{2 0}$

\begin{tabular}{lcccc}
\hline Test & Range of score & Mean & Median & SD \\
\hline Pre-test & $7-11$ & 8.15 & 9.5 & 1.27 \\
Post-test & $4-5$ & 4.2 & 4.5 & 0.4 \\
\hline
\end{tabular}

Table 4: Mean, standard deviation, mean difference, and $t$-value of pre-test and post-test quality of sleep scores in the experimental group, $n=20$

\begin{tabular}{lcccc}
\hline Test & Mean score & SD & Mean difference & t-value \\
\hline Pre-test & 8.15 & 1.27 & 3.95 & 15.41 \\
Post-test & 4.2 & 0.4 & & \\
\hline
\end{tabular}


Table 5: Frequency and percentage distribution of sample according to the quality of sleep in the control group, $n=20$

\begin{tabular}{|c|c|c|c|c|c|}
\hline \multirow[t]{2}{*}{ Quality of sleep } & \multirow[t]{2}{*}{ Range } & \multicolumn{2}{|c|}{ Pre-test } & \multicolumn{2}{|c|}{ Post-test } \\
\hline & & Frequency & Percentage & Frequency & Percentage \\
\hline Good & $0-4$ & - & - & - & - \\
\hline Poor & $5-21$ & 20 & 100 & 20 & 100 \\
\hline
\end{tabular}

Table 6: Range, mean, median, and SD of pre-test and post-test scores of quality of sleep in the control group, $n=20$

\begin{tabular}{lcccc}
\hline Test & Range of score & Mean & Median & SD \\
\hline Pre-test & $7-11$ & 8.4 & 9 & 1.32 \\
Post-test & $6-12$ & 8.3 & 9.5 & 1.67 \\
\hline
\end{tabular}

Table 7: Frequency and distribution of sample according to the post-test scores of quality of sleep in the experimental and control groups, $n=40$

\begin{tabular}{lccccc}
\hline $\begin{array}{l}\text { Quality of } \\
\text { sleep }\end{array}$ & \multicolumn{2}{c}{ Experimental group $(\boldsymbol{n = 2 0})$} & & \multicolumn{2}{c}{ Control group $(\boldsymbol{n}=\mathbf{2 0})$} \\
\cline { 2 - 3 } \cline { 5 - 6 } & Frequency & Percentage & & Frequency & Percentage \\
\hline Good $(0-4)$ & 16 & 80 & & - \\
Poor $(5-21)$ & 4 & 20 & & 20 & 100 \\
\hline
\end{tabular}

Table 8: Mean, SD, mean difference, and $t$-value of posttest scores of quality of sleep in the experimental and control groups, $n=40$

\begin{tabular}{lcccc}
\hline Group & Mean score & SD & Mean difference & $\boldsymbol{t}$-value \\
\hline Experimental & 4.2 & 0.4 & 4.1 & 10.58 \\
Control & 8.3 & 1.67 & & \\
\hline
\end{tabular}

research hypothesis was accepted. This shows that acupressure therapy was effective in maintaining quality of sleep.

\section{Association of post-test quality of sleep with selected baseline variables}

Association between post-test quality of sleep and baseline variables was analyzed using Chi-square test and Fisher's exact test.

To test the association, following hypothesis was stated, $\mathrm{H}_{3}$ - there will be significant association between post-test quality of sleep and the selected baseline variables. The findings suggested that none of the variables have significant association with post-test quality of sleep. " $P$ " $>0.05$ (at $5 \%$ level of significance) was considered for all the variables which clearly explains that there is no significant association between post-test quality of sleep and baseline variables.

\section{DISCUSSION}

Acupressure is an alternative therapy which is effective in the relief of stress-related ailments, is one of the nonpharmacological measures which play a key role improving quality of sleep. The present study was carried to find the effectiveness of acupressure on quality of sleep among the elderly. Results show that in pre-test, both the experimental and control groups, majority (100\%) of the elderly had poor quality of sleep. Post-test shows that in experimental group, $80 \%$ had good quality of sleep and $20 \%$ had poor quality of sleep following acupressure therapy. This clearly states that there is a positive effect of acupressure on quality of sleep among the elderly. The current study finding is supported by many other research studies. A similar study was conducted in the year 2018, in two old age homes in Madurai to assess the effectiveness of acupressure on improvement of sleep quality among the elderly. Quantitative approach with one group pretest-posttest design was used. PSQI was used to measure the sleep quality. All the subjects reported poor quality of sleep. Majority had moderate level of poor quality of sleep in pre-test (61.7\%). Following acupressure 43.3\% of subjects reported good quality of sleep. Acupressure was found to be significantly effective in improving sleep quality ${ }^{[10]}$ A similar finding reported in a study which was conducted in the year 2017, Acupressure, Sleep, and Quality of Life in Institutionalized Older Adults: A Randomized Control Trial with a Pre-Test and Post-Test Design. Sixty-two older nursing home residents were randomly assigned to an experimental group and a sham-controlled group. Results showed that the experimental group had significantly better scores on the PSQI during the intervention period. ${ }^{[11]}$ Also to support above study findings, an integrative review of acupressure interventions for older people: A focus on sleep quality, depression, anxiety, and agitation was conducted in the year 2020. A total of 255 articles were identified from the authentic sources and as well one article from crossreferences. From there, a total of 19 studies were included in this review. Nine studies consistently showed positive effects of acupressure on sleep quality. ${ }^{[12]}$ The study results are consistent with another study a randomized controlled clinical trial was conducted to test the effectiveness of acupressure on quality of sleep of elderly residing in a nursing home. The PSQI questionnaire was used as a screening tool to select 90 residents with moderate to marked sleep disturbances. The elders were randomly assigned to an acupressure group, a sham acupressure group, and a control group by balanced randomization method. There were significant differences between the acupressure group and the control group in subjective sleep quality. The findings of this study indicated that acupressure has an effect on improvement of sleep quality. ${ }^{[13]}$ Results are also consistent with one more study conducted during the year 2016, a randomized controlled trial, 108 hemodialysis patients were randomly divided into three groups: True acupressure, placebo acupressure, and no treatment. The two acupressure groups received treatment 3 times a week for 4 weeks during dialysis. Routine care only was provided for the no treatment group. The total PSQI score 
decreased significantly from $11.9 \pm 3.13$ to $6.2 \pm 1.93$ in the true acupressure group, from $11.3 \pm 3.69$ to $10.6 \pm 3.82$ in the sham acupressure group, and from $10.9 \pm 4.10$ to $10.7 \pm 3.94$ in the no treatment group. There was a significant difference between groups. ${ }^{[14]}$ Thereby, the researcher concludes that there was a significant improvement in quality of sleep after the acupressure therapy.

\section{ConcLusion}

The researcher concluded that there is a significant improvement in the quality of sleep among the elderly after acupressure therapy.

\section{AcKnowledgment}

- We extend a wholehearted thanks to Mr. Subrahmanya Nayak and Mrs. Savitha Shetty for their guidance

- We would like to express our deep sense of appreciation to the Mother Superior St. Joseph's Prashanth Nivas, Jeppu, Mangalore

- We are indebted to all the participants of St. Joseph's Prashanth Nivas, Jeppu, Mangalore, who were very disciplined, cooperative, and willing enough to participate in our study.

\section{REFERENCES}

1. Mrinalini C, Lewis AS. Medical Surgical Nursing: Assessment and Management of Clinical Problems. Netherlands: Elsevier Publication; 2011. p. 55-6.

2. Eliopoulos C. Gerontological Nursing. $7^{\text {th }}$ ed. United States: Lippincott Williams \& Wilkins, Wolter Kluwer Publication; 2010. p. 173-4.
3. Kamel NS, Gammack JK. Insomnia in the elderly: Cause, approach, and treatment. Am J Med 2006;119:463-9.

4. Youssef RM. Comprehensive health assessment of senior citizens in AlKarak governorate, Jordan. EMHJ East Mediterr Health J 2005;11:334-48.

5. Avidan AY. Epidemiology, Assessment, and Treatment of Insomnia in Elderly: Epidemiology of Insomnia in the Elderly. Available from: http://www.medscape.org/viewarticle/516282.

6. Wlash JK. Clinical and socioeconomic correlates of insomnia. J Clin Psychiatry 2004;65:13-9.

7. Su TP, Huang SR, Chou P. Prevalence and risk factors of insomnia in community-dwelling Chinese elderly: A Taiwanese urban area survey. Aust N Z J Psychiatry 2004;38:706-13.

8. Strangers S. Global Sleeplessness Epidemic. University of Warwick. Available from: http://www.strangers@warwick.ac.com. [Last accessed on $2015 \mathrm{Feb}$ ???].

9. Pappathi K. Ageing: Scientific Perspectives and Social Issues. Available from: http://www.sapnaonline.com/ageing-scientific-perspectivessocial-issues.com. [Last accessed on 2015 Jan 29].

10. Rajkumar DR. Effectiveness of acupressure on improvement of sleep quality among elderly. Indian J Contin Nurs Educ 2016;17:62.

11. Lai FC, Chen IH, Chen PJ, Chen IJ, Chien HW, Yuan CF. Acupressure, sleep, and quality of life in institutionalized older adults: A randomized controlled trial. J Am Geriatr Soc 2017;65:e103-8.

12. Hmwe NT, Browne G, Mollart L, Allanson V, Chan SW. An integrative review of acupressure interventions for older people: A focus on sleep quality, depression, anxiety, and agitation. Int J Geriatr Psychiatry 2019;34:381-96.

13. Reza H, Kian N, Pouresmail Z, Masood K, Bagher MS, Cheraghi MA. The effect of acupressure on quality of sleep in Iranian elderly nursing home residents. Complement Ther Clin Pract 2010;16:81-5.

14. Arab Z, Shariati AR, Asayesh H, Vakili MA, Bahrami-Taghanaki H, Azizi $\mathrm{H}$. A sham-controlled trial of acupressure on the quality of sleep and life in haemodialysis patients. Acupunct Med 2016;34:2-6.

How to cite this article: Denitha T, Rodrigues J. A Study to Evaluate the Effectiveness of Acupressure on Quality of Sleep among the Elderly in Selected Old Age Home at Mangalore, Karnataka. Int J Nurs Med Invest. 2020;5(3):33-37. 